\title{
Application and evaluation of nucleic acid sequence-based amplification, PCR and cryptococcal antigen test for diagnosis of cryptococcosis
}

\author{
Yanping Wang ${ }^{1 \dagger}$, Mi Yang $^{2 \dagger}$, Yun Xia ${ }^{1 *}$, Jia Yan ${ }^{1}$, Jiaqi Zou ${ }^{1}$ and Dawei Zhang ${ }^{1}$
}

\begin{abstract}
Background: Cryptococcosis is a major opportunistic invasive mycosis in immunocompromised patients, but it is also increasingly seen in immunocompetent patients. In the early stages of cryptococcosis, limitations of the detection method may hinder the diagnosis. A molecular diagnostic technique based on nucleic acid sequence-based amplification (NASBA) method was developed to fulfil the need for efficient diagnosis of cryptococcosis.

Methods: We compared the diagnostic performance of NASBA, PCR and cryptococcal antigen (CrAg) test (colloidal gold method) in clinical samples from 25 cryptococcosis patients (including 8 cryptococcal meningoencephalitis and 17 pulmonary cryptococcosis) who were categorized as proven cases $(n=10)$ and probable cases $(n=15)$ according to the revised EORTC/MSG definitions. 10 patients with non-Cryptococcus infection and 30 healthy individuals were categorized as control group.

Results: The lowest detection limit of NASBA was $10 \mathrm{CFU} / \mathrm{mL}$, and RNA of non-target bacteria or fungi was not amplified. The sensitivity of NASBA, PCR and colloidal gold method was $92.00 \%$ (95\% Cl 72.50-98.60\%), 64.00\% (95\% $\mathrm{Cl} 42.62-81.29 \%), 100.00 \%$ (95\% Cl 83.42-100.00\%), and the specificity was $95.00 \%$ (95\% Cl 81.79-99.13\%), 80.00\% (95\% Cl 63.86-90.39\%) and $82.50 \%$ (95\% Cl 66.64-92.11\%) respectively. The highest specificity (97.50\%), accuracy (95.38\%) and $k$ value (0.90) were achieved when both NASBA and colloidal gold results were positive.

Conclusions: NASBA is a new alternative detection method for cryptococcosis which is both accurate and rapid without expensive equipment and specialised personnel. It may be used as a tool for confirming current infection as well as monitoring the effectiveness of antifungal treatment. The use of NASBA to detect Cryptococcus RNA in blood samples is of great significance for the diagnosis of pulmonary cryptococcosis. The combination of NASBA and colloidal gold can improve the diagnostic accuracy of cryptococcosis.
\end{abstract}

Keywords: NASBA, PCR, Capsular polysaccharide antigen, Cryptococcosis

*Correspondence: xiayun12cn@aliyun.com

†Yanping Wang and Mi Yang contributed equally to this study and share the first authorship

${ }^{1}$ Department of Laboratory Medicine, The First Affiliated Hospital of Chongqing Medical University, 1 You Yi Road, Yuzhong District, Chongqing 400016, China

Full list of author information is available at the end of the article

\section{Background}

Cryptococcosis is a fungal infection caused by encapsulated yeasts of the phylum Basidiomycota, genus Cryptococcus. Cryptococcus neoformans (C. neoformans) and Cryptococcus gattii cause the majority of cryptococcal infections in immunocompromised patients, resulting in varying complications [1]. But there are also reports 
showing that pulmonary cryptococcosis occurs more frequently in immunocompetent patients than in immunocompromised ones [2]. According to the revised definitions of invasive fungal disease from the European Organization for Research and Treatment of Cancer/ Invasive Fungal Infections Cooperative Group and the National Institute of Allergy and Infectious Diseases Mycoses Study Group (EORTC/MSG) Consensus Group [3], laboratory tests such as culture, microscopic analysis and antigen detection, are of great significance for diagnosis of proven or probable cryptococcosis, especially for proven cryptococcal meningoencephalitis. Although isolation of the fungus from cultured tissue or body fluids (sputum, blood and cerebrospinal fluid) is the most commonly used detecting method in laboratories, it is relatively time-consuming for identifying the microorganisms [4]. In fact, direct microscopic examination is rapid, but the sensitivity is very low even if India ink staining is used [5], and fungal structures are only observed when the infection is advanced [6]. The detection of CrAg by colloidal gold method is one of the most helpful fungal routine tests, which is easy to use and has better sensitivity than other conventional methods for rapid diagnosis of early Cryptococcus infection [7, 8]. However, false-positive as well as false-negative results have been caused because of many factors such as rheumatoid factor, cross antigens of other fungi or bacterial and unknown non-specific proteins. Moreover, it is also unreliable for monitoring the efficacy of antifungal treatment $[9,10]$.

Recently, the diagnostic limitations and increasing incidence of fungal infections have prompted the development of tools for rapid and accurate diagnosis by using molecular methods based on nucleic acid amplification, including Polymerase Chain Reaction (PCR) and Nucleic acid sequence-based amplification (NASBA). Although in previous studies, PCR-based molecular methods provided both high sensitivity and specificity, the results were susceptible to DNA contamination [11]. NASBA assay has shown great potential in clinical application and has been successfully applied to detect bacteria, viruses, molds and parasites [12-15]. Compared to PCR, NASBA has a higher amplification efficiency because it can yield more than $10^{12}$ amplicons in as little as $30 \mathrm{~min}$ [16-18], which only takes about $2 \mathrm{~h}$ to perform each assay. Therefore, even if only a small amount of cryptococcal nucleic acid has been released from the fungal infection into blood or CSF, rapid amplification by NASBA can increase the positive rate. In our previous studies, the NASBA assay described by Park $C$ has been successfully validated in diagnosing invasive aspergillosis [19-21]. However, the use of NASBA for cryptococcal diseases has not been described so far. The aim of this study was to develop a
NASBA system to detect Cryptococcus RNA in serum or cerebrospinal fluid (CSF) for rapid diagnosis of cryptococcal infection.

\section{Methods}

\section{Fungal and bacterial strains}

Cryptococcus neoformans FY226, isolated from clinical samples, was cultured on blood agar at $37^{\circ} \mathrm{C}$ for $1-2$ days. It was identified as $C$. neoformans by ITS gene sequencing [22]. Spores of Cryptococcus were diluted with saline and quantified using a Neubauer chamber. A solution containing approximately $10^{5}$ spores was used for total RNA extraction. To assess the specificity of NASBA, the following strains of fungi and bacteria were used: Aspergillus fumigatus (A. fumigatus CMCCA1a), Fusarium moniliforme (F. moniliforme ATCC MYA-3629), Candida albicans (C. albicans ATCC 64548), Candida parapsilosis (C. parapsilosis ATCC 22019), Staphylococcus aureus (S. aureus ATCC 29213), Pseudomonas aeruginosa (P. aeruginosa ATCC 27853), Escherichia coli (E. coli ATCC 25922). All of the strains were cultured on blood agar at $37^{\circ} \mathrm{C}$ for $1-2$ days and the total RNA was extracted with Trizol reagent (Invitrogen, California, America) strictly following the Manufacturer's instructions.

\section{Patient populations and clinical samples}

A total of 65 inpatients were enrolled from 2017 to 2019 in the First Affiliated Hospital of Chongqing Medical University and categorized as proven cases $(n=10)$, probable cases $(n=15)$ and non-cryptococcosis $(n=40)$ according to the revised EORTC/MSG criteria. A proven cryptococcal meningoencephalitis is based on positive $\mathrm{CrAg}$ in CSF or a positive result of an India ink preparation of CSF. To define as a proven pulmonary cryptococcosis, it is required that yeasts cells or spores were detected by histological analysis or culture of a tissue specimen which was taken from the infected site of lungs by a sterile procedure, or blood culture is positive. Probable pulmonary cryptococcosis requires the presence of a host factor, a clinical criterion, and symptoms consistent with the disease entity, and mycological evidence (encapsulated budding yeasts cells or spores in bronchial alveolar lavage or sputum be detected by India ink staining or in the culture, or Cryptococcus antigen test in bronchial alveolar lavage, sputum, serum be positive) [23]. Of the 10 proven cases, there were 8 cryptococcal meningoencephalitis and 2 pulmonary cryptococcosis while 15 probable cases were all pulmonary cryptococcosis. 10 patients with nonCryptococcus infection (including two tuberculosis, two bacterial infections, three fungal infections other than Cryptococcus and three autoimmune diseases) and 30 healthy individuals without any clinical symptoms of bacterial, fungal or parasitic infection and chronic diseases 
were categorized as control group. Proven and probable cases were selected on the solid basis of sample availability and diagnosis. For patients with cryptococcal meningoencephalitis, the collected samples were CSF, while for patients with pulmonary cryptococcosis and control group, the collected samples were serum. Serum or CSF specimen were all collected prior to any antifungal agents were used and stored at $-80^{\circ} \mathrm{C}$.

\section{Cryptococcus RNA extraction}

In order to determine the analytical sensitivity of NASBA assays, spore suspensions of $C$. neoformans FY226 with a certain concentration $(106 \mathrm{CFU} / \mathrm{mL}, 105 \mathrm{CFU} / \mathrm{mL}$, $104 \mathrm{CFU} / \mathrm{mL}$ ) were prepared by counting with a microscope. $100 \mu \mathrm{L}$ of fungal suspension ground in mortar (free of Rnase) with liquid nitrogen was used for RNA extraction by a total RNA rapid extraction kit (Trizol) according to our previous study [21]. For samples of clinical patients, total RNA was extracted from serum or CSF using a blood/liquid sample total RNA rapid extraction kit (BioTeke, Beijing, China). In short, $250 \mu \mathrm{L}$ of serum or CSF and $750 \mu \mathrm{L}$ of RLS lysis buffer were mixed in a $1.5 \mathrm{~mL}$ microcentrifuge tube and incubated at room temperature for $10 \mathrm{~min}$. Then $150 \mu \mathrm{L}$ of chloroform was added, and the tube was vigorously vortexed for $15 \mathrm{~s}$ followed by incubation at room temperature for $3 \mathrm{~min}$. After the mixture was centrifuged at $12,000 \times g$ for $10 \mathrm{~min}$ at $4{ }^{\circ} \mathrm{C}$, the aqueous phase was transferred to the spin column AC and mixed with $600 \mu \mathrm{L} 70 \%$ ethanol, followed by sequential washing of the column with buffer RE and buffer RW. Finally, RNA was eluted with $30 \mu \mathrm{L}$ RNasefree water and stored at $-80^{\circ} \mathrm{C}$ for further use.

\section{Primers}

A highly conserved capsular-associated protein (CAP10) region specific to Cryptococcus genus was chosen as the detection target, and the primer sequence was designed by bioinformatics method according to previous reports (P1:5'-AATTCTAATACGACTCACTATAGGGCCA AGCCCCCAAACCTCCCATAC-3'; P2:5'-AACGCG TACCATTCATCAAAGCC-3') [24]. This pair of primers was used to amplify a 229 nucleotide fragment of the target RNA.

\section{NASBA assay of cultured clinical strains and clinical samples}

For NASBA reaction, Cryptococcus RNA sample $(5 \mu \mathrm{L})$ was suspended in $10 \mu \mathrm{L}$ of amplification buffer reagent consisting of $2 \mathrm{mmol} / \mathrm{L}$ each NTP (Takara Bio), $70 \mathrm{mmol} / \mathrm{L} \mathrm{KCl}, 40 \mathrm{mmol} / \mathrm{L}$ Tris- $\mathrm{HCl}(\mathrm{pH} 8.5)$, $12 \mathrm{mmol} / \mathrm{L} \mathrm{MgCl}_{2}, 5 \mathrm{mmol} / \mathrm{L}$ dithiothreitol, $0.375 \mathrm{~mol} / \mathrm{L}$ sorbitol, $0.4 \mathrm{mmol} / \mathrm{L}$ each primer, and $12 \mathrm{U}$ ribonuclease inhibitor (Promega, Fitchburg, WI, USA) in 10\% dimethyl sulfoxide. The mixture was incubated at $65^{\circ} \mathrm{C}$ for $5 \mathrm{~min}$, then the primer was annealed at $41{ }^{\circ} \mathrm{C}$ for $5 \mathrm{~min}$, followed by addition of $5 \mu \mathrm{L}$ enzyme mixture (40 U T7 RNA polymerase (Promega), $0.1 \mathrm{U}$ RNase $\mathrm{H}, 8 \mathrm{U}$ avian myeloblastosis virus reverse transcriptase (Takara Bio) and $2.0 \mu \mathrm{g}$ bovine serum albumin) [25]. The final mixture was amplified isothermally at $41{ }^{\circ} \mathrm{C}$ for $90 \mathrm{~min}$, and the amplification products were analyzed by $1 \%$ agarose gel electrophoresis. To detect any contamination, an equal volume of RNase-free water was used as a negative control and RNA extracted from C. neoformans in pure culture was used as a positive control in all NASBA assays.

\section{DNA extraction and PCR assay}

DNA was extracted from serum or CSF using a QIAamp blood/liquid mini kit (Qiagen, Hilden, Germany) according to the manufacturer's instructions. Briefly, $200 \mu \mathrm{L}$ of serum or CSF was mixed with $20 \mu \mathrm{L}$ protease solution in a microcentrifuge tube and the tube was vigorously vortexed for $15 \mathrm{~s}$ after addition of $200 \mu \mathrm{L}$ AL buffer, followed by incubation at $56{ }^{\circ} \mathrm{C}$ for $10 \mathrm{~min}$. Then $200 \mu \mathrm{L}$ absolute ethanol was added to the mixture and transferred to a QIAamp mini spin column. After centrifugation of the column at $6000 \times g$ for $1 \mathrm{~min}$, the filtrate was discarded and the column was washed sequentially with $500 \mu \mathrm{L}$ buffer AW1, $500 \mu \mathrm{L}$ buffer AW2 as well as $200 \mu \mathrm{L}$ buffer AE. Finally, DNA was eluted with $40 \mu \mathrm{L}$ buffer AE and stored at $-20{ }^{\circ} \mathrm{C}$. Purified DNA was amplified by PCR assay using previously reported primers targeting the CAP10 gene (P1:5'-CCAAGCCCCCAAACC TCCCATAC-3', P2:5'-AACGCGTACCATTCATCA AAGCC-3) [24]. The PCR system consisted of $3 \mu \mathrm{L}$ of purified DNA in a total PCR volume of $25 \mu \mathrm{L}$ with $1.0 \mu \mathrm{L}$ each primer, $12.5 \mu \mathrm{L}$ Taq polymerase (Takara Bio) and $7.5 \mu \mathrm{L}$ sterile pure water. The mixture was incubated at $94{ }^{\circ} \mathrm{C}$ for $5 \mathrm{~min}, 35$ cycles of $45 \mathrm{~s}$ at $94{ }^{\circ} \mathrm{C}$, followed by $56{ }^{\circ} \mathrm{C}$ for $45 \mathrm{~s}$ and $72{ }^{\circ} \mathrm{C}$ for another $45 \mathrm{~s}$, and the final extension was at $72{ }^{\circ} \mathrm{C}$ for $7 \mathrm{~min}$. Negative control (template as an equal volume of pure water) and positive control (DNA extracted from C. neoformans in pure culture) were also included in each run.

\section{Cryptococcal capsular polysaccharide antigen detection}

Colloidal gold kits (IMMY, Norman, OK) were used to detect Cryptococcus capsular polysaccharide antigen in clinical samples of this study according to the manufacturer's recommendations. The whole blood sterile samples or CSF were collected by routine aseptic method. After serum and CSF supernatant were separated, $40 \mu \mathrm{L}$ of sample dilution was added into a small test tube and mixed with $40 \mu \mathrm{L}$ serum or CSF supernatant. Finally, a test strip was inserted into the mixture and the result was read after $10 \mathrm{~min}$. The result was negative if there was 
only the presence of quality control line on the test strip. If there were both quality control line and test line, the result was judged as positive, and only the test line indicated an invalid test.

\section{Statistical analysis}

IBM SPSS Statistics software package version 22.0 (IBM, Armonk, NY) was used to evaluate the performance parameters of each assay through the construction of $2 \times 2$ tables. To calculate the sensitivity of these three methods, positive results from patients with proven or probable cryptococcosis based on the EORTC/MSG criteria were served to be true positive. For calculation of the specificity, negative results from patients without evidence of cryptococcosis according to the EORTC/MSG criteria were considered to be true negative. The sensitivity, specificity, positive predictive value (PPV), negative predictive value (NPV), positive likelihood ratio, negative likelihood ratio, and accuracy were calculated for each assay. The comparison between two methods was performed by paired diagnosis test design using $\mathrm{McNe}$ mar or Fisher's exact test with a $P$ value of $\leq 0.05$ being considered significant. The Youden index was calculated to assess the ability of each assay to identify real patients and non-patients. The $\mathrm{k}$ statistic was applied to evaluate the consistency of the three methods [26] and interpreted as follows: excellent agreement between tests, $k>0.80$; substantial agreement, $0.60<\mathrm{k} \leq 0.80$; moderate agreement, $0.40<\mathrm{k} \leq 0.60$; and poor agreement, $\mathrm{k} \leq 0.40$.

\section{Results}

\section{Analytical specificity of NASBA}

The positive result was a $229 \mathrm{bp}$ fragment of cultured $C$. neoformans FY226, which matched the CAP10 gene of C. neoformans standard strain $\mathrm{H} 99$ best after sequencing and BLAST analysis in NCBI database. No positive results were demonstrated for control strains $A$. fumigatus, F. moniliforme, C. albicans, C. parapsilosis, S. aureus, P. aeruginosa and E. coli (Fig. 1).

\section{Analytical sensitivity of NASBA}

The analytical sensitivity of NASBA was acquired by using $1 \%$ agarose gel electrophoresis to analyze tenfold serial dilution of $C$. neoformans FY226 genomic RNA (Fig. 2). The lowest detection limit of NASBA was $10 \mathrm{CFU} / \mathrm{mL}$ after two repeated experiments.

\section{Comparison of individual assay performance}

The results of 65 clinical specimens detected by NASBA, PCR and colloidal gold assays for CrAg were listed in Table 1. The NASBA results of 10 proven cases were all positive, and 13 of 15 probable cases were positive for it. The diagnostic parameters of sensitivity, specificity,

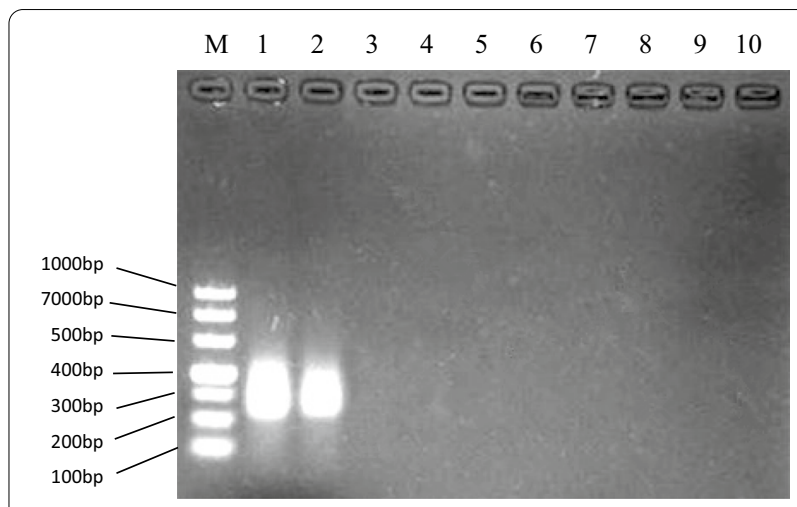

Fig. 1 Electrophoresis results of NASBA products from different strains. M: DL1000bp DNA marker; 1-2: C. neoformans (FY 226); 3: A. fumigatus (CMCCA1a); 4: F. moniliforme (ATCC MYA-3629); 5: C. albicans (ATCC 64548); 6: C. parapsilosis (ATCC 22019); 7: S. aureus (ATCC 29213); 8: P. aeruginosa (ATCC 27853); 9: E. coli (ATCC 25922); 10: Negative control

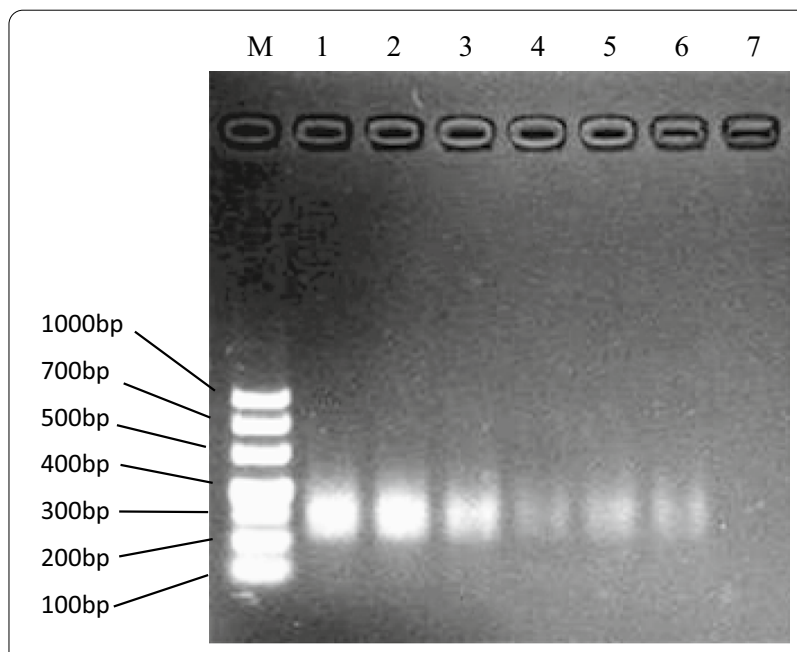

Fig. 2 Electrophoresis analysis of NASBA products with gradient C. neoformans spores. M: DL1000bp DNA marker; 1-3: RNA extracted from the spore suspension of $C$. neoformans at a concentration of $10^{6} \mathrm{CFU} / \mathrm{mL}, 10^{5} \mathrm{CFU} / \mathrm{mL}$, and $10^{4} \mathrm{CFU} / \mathrm{mL}$, which was used as a template for NASBA; 4-7: RNA extracted from the spore suspension with a concentration of $10^{4} \mathrm{CFU} / \mathrm{mL}$ was diluted 10-10,000 times, and the concentrations corresponded to electrophoresis bands of $10^{3} \mathrm{CFU} / \mathrm{mL}, 10^{2} \mathrm{CFU} / \mathrm{mL}, 10^{1} \mathrm{CFU} / \mathrm{mL}$, and $10^{\circ} \mathrm{CFU} / \mathrm{mL}$, respectively

accuracy, Kappa value, etc. were calculated for each assay (Table 2). The colloidal gold method had the highest sensitivity, while NASBA had the highest specificity among the three methods. Hypothesis testing of sensitivity revealed that NASBA and colloidal gold were significantly greater than that of PCR. There were no significant differences observed in sensitivity and specificity between NASBA and colloidal gold test. Overall, the 
NASBA assay performed best in accuracy, positive likelihood ratio, positive predictive value, Youden index, and Kappa value, while colloidal gold performed best in terms of negative likelihood ratio and negative predictive value.

\section{Comparison of combined assay performance}

We further analyzed the diagnostic efficacy of combined detection of NASBA, PCR and colloidal gold for cryptococcal disease, the diagnostic parameters of sensitivity, specificity, accuracy, and Kappa value were calculated and results are shown in Table 3. When both NASBA and colloidal gold results were positive, the highest specificity, accuracy and $\mathrm{k}$ value were obtained.

\section{Discussion}

Cryptococcal disease, once rare, has now become a major fungal infection in immunocompromised population worldwide, mainly in HIV-infected patients and people undergoing immunosuppressive therapy as well as those with lymphoproliferative disorders [27]. Early diagnosis of cryptococcal infection is critical to improving clinical outcomes. The detection of $\mathrm{CrAg}$ can greatly increase the diagnosis rate of cryptococcosis, but it can also lead

Table 1 NASBA, PCR and colloidal gold results of clinical samples

\begin{tabular}{|c|c|c|c|c|c|c|c|}
\hline \multirow[t]{2}{*}{ EORTC/MSG } & \multicolumn{2}{|c|}{ NASBA } & \multicolumn{2}{|c|}{ PCR } & \multicolumn{2}{|c|}{ Colloidal gold } & \multirow[t]{2}{*}{ Total } \\
\hline & + & - & + & - & + & - & \\
\hline Proven cases $(n=10)$ & 10 & 0 & 7 & 3 & 10 & 0 & 10 \\
\hline Probable cases $(n=15)$ & 13 & 2 & 9 & 6 & 15 & 0 & 15 \\
\hline Control group $(n=40)$ & 2 & 38 & 8 & 32 & 7 & 33 & 40 \\
\hline Total & 25 & 40 & 24 & 41 & 32 & 33 & 65 \\
\hline
\end{tabular}

EORTC/MSG, European Organization for Research and Treatment of Cancer/Invasive Fungal Infections Cooperative Group and the National Institute of Allergy and Infectious Diseases Mycoses Study Group

Table 2 Clinical diagnostic performance of NASBA, PCR and colloidal gold

\begin{tabular}{|c|c|c|c|}
\hline Parameter & NASBA & PCR & Colloidal gold \\
\hline Sensitivity $[\%(95 \%$ Cl)] & $92.00(72.50-98.60)$ & $64.00(42.62-81.29)^{*}$ & $100.00(83.42-100.00)$ \\
\hline Specificity [\% (95\% Cl)] & $95.00(81.79-99.13)$ & $80.00(63.86-90.39)$ & $82.50(66.64-92.11)$ \\
\hline Accuracy $[\%]$ & 93.85 & 73.85 & 89.23 \\
\hline Positive likelihood ratio & $18.40(4.74-71.39)$ & $3.20(1.61-6.35)$ & $5.71(2.92-11.20)$ \\
\hline Negative likelihood ratio & $0.08(0.02-0.32)$ & $0.45(0.26-0.77)$ & $0.00(0.00-\mathrm{NaN})$ \\
\hline Positive predictive value [\% (95\% CI)] & $92.00(72.50-98.60)$ & $66.67(44.69-83.57)$ & $78.13(59.56-90.06)$ \\
\hline Negative predictive value [\% (95\% CI)] & $95.00(81.79-99.13)$ & $78.05(61.97-88.89)$ & $100.00(87.02-100.00)$ \\
\hline Youden index & 0.87 & 0.44 & 0.83 \\
\hline Kappa & 0.87 & 0.44 & 0.78 \\
\hline
\end{tabular}

Best performance values are highlighted in bold. ${ }^{*} \mathrm{P}<0.05$ versus NASBA, colloidal gold

Table 3 Combined diagnostic performance of NASBA, PCR or colloidal gold

\begin{tabular}{|c|c|c|c|c|c|c|}
\hline Test combination & $\begin{array}{l}\text { Proven/probable } \\
\text { cases }(n=25)\end{array}$ & $\begin{array}{l}\text { Control group } \\
(n=40)\end{array}$ & Sensitivity (\%) & Specificity (\%) & Accuracy (\%) & Kappa \\
\hline $\mathrm{NASBA}+$ or $\mathrm{PCR}+$ & 23 & 8 & 92.00 & 80.00 & 84.62 & 0.69 \\
\hline $\mathrm{NASBA}+$ and $\mathrm{PCR}+$ & 16 & 1 & 64.00 & 97.50 & 84.62 & 0.65 \\
\hline NASBA+ or colloidal gold+ & 25 & 7 & 100.00 & 82.50 & 89.23 & 0.78 \\
\hline NASBA+ and colloidal gold+ & 23 & 1 & 92.00 & 97.50 & 95.38 & 0.90 \\
\hline PCR+ or colloidal gold+ & 25 & 13 & 100.00 & 67.50 & 80.00 & 0.62 \\
\hline PCR+ and colloidal gold+ & 16 & 1 & 64.00 & 97.50 & 84.62 & 0.65 \\
\hline NASBA+ or PCR+ or colloidal gold+ & 25 & 14 & 100.00 & 65.00 & 78.46 & 0.59 \\
\hline NASBA+, PCR+ and colloidal gold+ & 16 & 0 & 64.00 & 100.00 & 86.15 & 0.69 \\
\hline
\end{tabular}

Best performance values are highlighted in bold 
to some false positive results. And for pulmonary cryptococcosis, because of its various clinical manifestations, the diagnosis is relatively complex and easy to miss. In fact, the clinical symptoms of pulmonary cryptococcal infection are based on the observation of abnormalities in X-rays, but such findings are also related to Mycobacterium tuberculosis infection in patients with proven or suspected HIV infection [28]. Tuberculosis may overshadow other opportunistic infections, leading to delayed diagnosis and appropriate treatment [29]. Therefore, there is an urgent need for a new laboratory test other than $\mathrm{CrAg}$ as another important test method for the diagnosis of cryptococcosis.

Molecular diagnostics have been proven to be very promising for the diagnosis of fungal infection [30]. This is the first study to describe NASBA assay for the analysis of cryptococcal RNA in clinical samples. In general, $18 \mathrm{~S}$ rRNA is used as a common amplification target in the NASBA process of invasive aspergillosis [20, 21]. However, CAP10 gene is considered to be a better target for the diagnosis of cryptococcosis because it can encode a highly conserved capsule-associated protein which is specific for the Cryptococcus genus and has become a most important factor determining the pathogenicity of Cryptococcus neoformans [24]. In our report, the primers used in NASBA system were aligned in BLAST and ensured fine specificity, the specificity of NASBA was proved by the non-specific amplification signal when RNA of nontarget bacteria or fungi was used as templates.

The lowest detection limit of NASBA was $10 \mathrm{CFU/}$ $\mathrm{mL}$, and the sensitivity of NASBA in clinical samples was significantly greater than that of PCR $(P<0.05)$. NASBA possesses a higher inherent amplification capability because each cDNA template produces numerous RNA copies in each cycle, while each cDNA merely doubles in number at each cycle of PCR. NASBA has comparable sensitivity to colloidal gold method and the results of 10 proven cases were all positive. At the same time, of the 8 proven patients with cryptococcal meningoencephalitis, 5 had positive CSF culture results and only 3 had positive India ink results. Of the 2 proven and 15 probable patients with pulmonary cryptococcosis, bronchial alveolar lavage or sputum culture results were all negative. Therefore, compared with India ink staining or culture, the positive rate of NASAB was much higher. There were no statistical differences in the specificity of NASBA, PCR, and colloidal gold due to the small sample size. However, the specificity of NASBA reaches $95 \%$, suggesting that it was an important method for confirming the diagnosis of cryptococcosis. The high specificity of NASBA may be that NASBA only allows amplification of template nucleic acids with T7 promoter and the thermal denaturation is absent, which can avoid the potential risk of contamination by non-target microbial nucleic acid or homologous DNA [31]. Since NASBA had the best performance in accuracy, positive likelihood ratio, positive predictive value, Youden index and $\mathrm{k}$ value among the three methods, it may be used for confirming cryptococcosis cases in routine laboratories. However, NASBA requires high quality specimens since RNA is easily degraded. And compared with DNA extraction, the RNA extraction process is more complicated and mainly operated manually, which may limit its wide use in fungal detection.

Our study yielded negative results in two patients with probable pulmonary cryptococcosis. We traced the specimen and found that one sample has been stored at $-80^{\circ} \mathrm{C}$ for more than 1 year, the RNA in the specimen may have been degraded. For another negative result, the reason was that the patient had received antifungal therapy before admission, the Cryptococcus spores had been killed by antifungal drugs and could not release free RNA into blood. In contrast, the capsular polysaccharide antigen has a relatively long metabolic time lasting for several months, so colloidal gold result remains positive. The positive result of antigen will continue for a long time even after successful treatment. While for NASBA, the positive result can quickly turn negative once antifungal drugs are used. Therefore, NASBA is of great significance for confirming current cryptococcal infections, and may be used to monitor the effectiveness of antifungal treatment. However, there is also a clear limitation to this test that patients on empiric therapy prior to testing would be missed, leading to false negative results.

In present study, colloidal gold is the most sensitive assay among the three methods, the sensitivity appears to be consistent with that reported by Antinori [32]. Nevertheless, the specificity of colloidal gold is only $82.50 \%$. To our knowledge, the specificity of colloidal gold technique is decreased due to the possibility of false-positive results, and it has previously been reported that $\mathrm{CrAg}$ cross-reacts with antigens of some fungi or bacteria such as Trichosporon beigelii and Ustilago maydis [33, 34]. The colloidal gold yielded 7 positive results for 40 non-Cryptococcus infection samples in this study. We followed up 5 of them, the clinical diagnosis of these five individuals involved one tuberculosis, two fungal infections other than Cryptococcus and two cases of autoimmune diseases. These false-positive results are probably due to that the presence of corresponding antigen in serum crossreacts with $\mathrm{CrAg}$, pronase has not been used in samples may be another important reason [35]. Importantly, we should also be aware of the condition defined as asymptomatic cryptococcal antigenemia, in which individuals with no symptoms may have positive antigen tests. The revised EORTC/MSG criteria recommend that such 
individuals may need to be followed and require treatment [36]. The colloidal gold method performed best in terms of negative likelihood ratio and negative predictive value, indicating that colloidal gold assay is suitable for screening patients suspected of Cryptococcus infection.

Although PCR assay has been reported to be recommended for the diagnosis of cryptococcal infection [37], its sensitivity in current study was significantly lower than the other two methods, even lower than previous reports [38]. The difference may be caused by the type of specimen selected. Most of the previous research groups had chosen cerebrospinal fluid as research specimen, while the subjects in this study were mainly serum specimens. Due to the neurotropic properties of Cryptococcus, most of them spread to the central nervous system through lung, reach pia mater, grow and reproduce massively [39]. Therefore, a large amount of Cryptococcus is enriched in cerebrospinal fluid while only a small amount of free nucleic acid is released from the fungal infection into blood, which leads to its low positive rate.

Combining the detection results of NASBA, PCR and colloidal gold to further explore their diagnostic efficacy for cryptococcosis, we found that when both NASBA and colloidal gold results were positive, the highest specificity, accuracy and $k$ value could be obtained without obvious reduction of sensitivity. The combination of NASBA and colloidal gold can improve the diagnostic accuracy of cryptococcosis as well as achieve a highest agreement with the EORTC/MSG criteria, which is more beneficial to the diagnosis of cryptococcosis.

\section{Conclusions}

This is the first report to describe NASBA for the diagnosis of Cryptococcus infection. The results showed that NASBA had good sensitivity and high specificity (absence of cross-reactivity with other unrelated bacteria or fungi). It may not only be used as a useful tool for rapid and accurate diagnosis of cryptococcosis but also for monitoring the effectiveness of antifungal treatment. We do not recommend the use of CSF for detection of NASBA because antigen detection is sensitive enough for the diagnosis of cryptococcal meningoencephalitis. However, the use of NASBA to detect Cryptococcus RNA in blood samples is of great significance for the diagnosis of pulmonary cryptococcosis. NASBA is suitable for use in less developed laboratories because it can be performed without any expensive equipment and specialised personnel. The combination of NASBA and colloidal gold can improve the diagnostic accuracy and is particularly useful in specific clinical situation (The negative colloidal gold result has an exclusion value, while the positive NASBA result has a confirmed value).

\section{Limitations}

Of course, there are some limitations of this study. First of all, this is a retrospective study with a small number of cases, we will further expand the sample size in subsequent studies. Secondly, we did not compare the cost and operation time of the three methods because compared with PCR or colloidal gold, NASBA is mainly operated manually without commercial kits and automated extraction platforms. Finally, we did not use a molecular beacon in the NASBA process, the detection of gel electrophoresis is cumbersome with a qualitative result, and weak positive results are not easy to observe.

\section{Abbreviations}

NASBA: Nucleic acid sequence-based amplification; EORTC/MSG: European Organization for Research and Treatment of Cancer/Invasive Fungal Infections Cooperative Group and the NIH National Institute of Allergy and Infectious Diseases Mycoses Study Group; CSF: Cerebral spinal fluid; C. neoformans: Cryptococcus neoformans; A. fumigatus: Aspergillus fumigatus; F. moniliforme: Fusarium moniliforme; C. albicans: Candida albicans; C. parapsilosis: Candida parapsilosis; S. aureus: Staphylococcus aureus; P. aeruginosa: Pseudomonas aeruginosa; E. coli: Escherichia coli; PPV: Positive predictive value; NPV: Negative predictive value.

\section{Acknowledgements \\ We would like to thank the staffs and director of Laboratory Medicine for their support and assistance in samples collection and laboratory work. \\ Authors' contributions \\ YW and MY collected clinical samples, performed NASBA and analyzed the experiment data, they were major contributors in writing the manuscript. YX designed the study, supervised all the experiments and revised the manu- script. JY, JZ and DZ performed PCR, colloidal gold test and collected clinical data, respectively. All authors read and approved the final manuscript.}

\section{Funding \\ Funding was provided by "the Project of National Clinical Key-discipline Construction" (2010 (305)), "the Fundamental and Front Research Funds of Chongqing" (20160129) and "the Project of Precision Medical Data Integration Technology Research and Big Data Analysis Construction (2017YFC0909902). The funding body had no role in the design of the study and collection, analy- sis, and interpretation of data and in writing the manuscript.}

\section{Availability of data and materials}

The datasets generated and analyzed during the current study are available from the corresponding author on reasonable request.

\section{Declarations}

\section{Ethics approval and consent to participate}

Since this article is a retrospective anonymous performance evaluation using residual clinical samples with no impact on patient management, the ethics committee of The First Affiliated Hospital of Chongqing Medical University agreed to waive the informed consent and passed the ethical review.

\section{Consent for publication \\ Not applicable.}

\section{Competing interests}

The authors declare that they have no competing interests.

\section{Author details}

${ }^{1}$ Department of Laboratory Medicine, The First Affiliated Hospital of Chongqing Medical University, 1 You Yi Road, Yuzhong District, Chongqing 400016, China. ${ }^{2}$ Department of Clinical Laboratory, Chengdu Women's and Children's 
Central Hospital, School of Medicine, University of Electronic Science and Technology of China, Chengdu 611731, China.

Received: 9 December 2019 Accepted: 10 September 2021 Published online: 29 September 2021

\section{References}

1. Cogliati M. Global molecular epidemiology of Cryptococcus neoformans and Cryptococcus gattii: an atlas of the molecular types. Scientifica (Cairo). 2013;2013:675213.

2. Liu K, Ding H, Xu B, You R, Xing Z, Chen J, Lin Q, Qu J. Clinical analysis of non-AIDS patients pathologically diagnosed with pulmonary cryptococcosis. J Thorac Dis. 2016;8(10):2813-21.

3. De Pauw B, Walsh TJ, Donnelly JP, Stevens DA, Edwards JE, Calandra T, et al. Revised definitions of invasive fungal disease from the European Organization for Research and Treatment of Cancer/Invasive Fungal Infections Cooperative Group and the National Institute of Allergy and Infectious Diseases Mycoses Study Group (EORTC/MSG) Consensus Group. Clin Infect Dis. 2008;46(12):1813-21.

4. Buitrago MJ, Cuenca-Estrella M. Current epidemiology and laboratory diagnosis of endemic mycoses in Spain. Enferm Infecc Microbiol Clin. 2012;30(7):407-13 (In Spanish).

5. Kwizera R, Akampurira A, Williams D, Boulware DR, Meya DB, ASTRO-CM Study Team. Acridine orange fluorescent microscopy is more sensitive than India ink light microscopy in the rapid detection of cryptococcosis among CrAg positive HIV patients. PLoS ONE. 2017;12(7):e0182108.

6. Qureshi A, Wray D, Rhome R, Barry W, Del Poeta M. Detection of antibody against fungal glucosylceramide in immunocompromised patients: a potential new diagnostic approach for cryptococcosis. Mycopathologia. 2012;173(5-6):419-25.

7. Boulware DR, Rolfes MA, Rajasingham R, von Hohenberg M, Qin Z, Taseera K, et al. Multisite validation of cryptococcal antigen lateral flow assay and quantification by laser thermal contrast. Emerg Infect Dis. 2014;20(1):45-53.

8. Pongsai P, Atamasirikul K, Sungkanuparph $\mathrm{S}$. The role of serum cryptococcal antigen screening for the early diagnosis of cryptococcosis in HIV-infected patients with different ranges of CD4 cell counts. J Infect. 2010;60(6):474-7.

9. Kauffman CA, Bergman AG, Severance PJ, McClatchey KD. Detection of cryptococcal antigen. Comparison of two latex agglutination tests. Am J Clin Pathol. 1981;75(1):106-9.

10. Borges MASB, Araújo Filho JAD, Soares RDBA, Vidal JE, Turchi MD. Falsenegative result of serum cryptococcal antigen lateral flow assay in an HIV-infected patient with culture-proven cryptococcaemia. Med Mycol Case Rep. 2019;26:64-6.

11. Corless CE, Guiver M, Borrow R, Edwards-Jones V, Kaczmarski EB, Fox AJ. Contamination and sensitivity issues with a real-time universal $16 \mathrm{~S}$ rRNA PCR. J Clin Microbiol. 2000;38(5):1747-52.

12. Kievits T, van Gemen B, van Strijp D, Schukkink R, Dircks M, Adriaanse $H$, et al. NASBA isothermal enzymatic in vitro nucleic acid amplification optimized for the diagnosis of HIV-1 infection. J Virol Methods. 1991;35(3):273-86.

13. Tauriainen S, Dadu E, Oikarinen M, Oikarinen S, Hyöty H. Amplifying control RNA for RT- PCR applications by nucleic acid sequence based amplification (NASBA). J Virol Methods. 2006;132(1-2):222-6.

14. van der Meide WF, Peekel I, van Thiel PP, Schallig HD, de Vries HJ, Zeegelaar JE, et al. Treatment assessment by monitoring parasite load in skin biopsies from patients with cutaneous leishmaniasis, using quantitative nucleic acid sequence- based amplification. Clin Exp Dermatol. 2008;33(4):394-9.

15. Monis PT, Giglio S. Nucleic acid amplification-based techniques for pathogen detection and identification. Infect Genet Evol. 2006;6(1):2-12.

16. Compton J. Nucleic acid sequence-based amplification. Nature. 1991;350(6313):91-2.

17. Mercier-Delarue S, Vray M, Plantier JC, Maillard T, Adjout Z, de Olivera F, et al. Higher specificity of nucleic acid sequence-based amplification isothermal technology than of real-time PCR for quantification of HIV-1 RNA on dried blood spots. J Clin Microbiol. 2014;52(1):52-6.
18. Zhao Y, Park S, Kreiswirth BN, Ginocchio CC, Veyret R, Laayoun A, et al. Rapid real-time nucleic acid sequence-based amplification molecular beacon platform to detect fungal and bacterial bloodstream infections. J Clin Microbiol. 2009;47(7):2067-78.

19. Park C, Kwon EY, Shin NY, Choi SM, Kim SH, Park SH, et al. Evaluation of nucleic acid sequence based amplification using fluorescence resonance energy transfer (FRET-NASBA) in quantitative detection of Aspergillus 18S rRNA. Med Mycol. 2011;49(1):73-9.

20. Wang L, He Y, Xia Y, Su X, Wang H, Liang S. Retrospective comparison of nucleic acid sequence-based amplification, real-time PCR, and galactomannan test for diagnosis of invasive aspergillosis. J Mol Diagn. 2014;16(5):584-90

21. Du L, Xia Y, He Y, Pu Q, Hua R, Wu W. Development and evaluation of enzyme-linked immunosorbent assay of nucleic acid sequence-based amplification for diagnosis of invasive aspergillosis. AMB Express. 2016;6(1):91

22. Arbefeville S, Harris A, Ferrieri P. Comparison of sequencing the D2 region of the large subunit ribosomal RNA gene (MicroSEQ) versus the internal transcribed spacer (ITS) regions using two public databases for identification of common and uncommon clinically relevant fungal species. J Microbiol Methods. 2017;140:40-6.

23. Shirley RM, Baddley JW. Cryptococcal lung disease. CurrOpinPulmMed. 2009; 15(3):254-60.

24. Chang YC, Kwon-Chung KJ. Isolation, characterization, and localization of a capsule-associated gene, CAP10, of Cryptococcus neoformans. J Bacteriol. 1999;81(18):5636-43.

25. Gill P, Ramezani R, Amiri MV, Ghaemi A, Hashempour T, Eshraghi N, et al. Enzyme-linked immunosorbent assay of nucleic acid sequencebased amplification for molecular detection of M. tuberculosis. Biochem Biophys Res Commun. 2006;347(4):1151-7.

26. White PL, Parr C, Thornton C, Barnes RA. Evaluation of real-time PCR, galactomannan enzyme-linked immunosorbent assay (ELISA), and a novel lateral-flow device for diagnosis of invasive aspergillosis. J Clin Microbiol. 2013;51(5):1510-6.

27. Rosen MJ. Pneumonia in patients with HIV infection. Med Clin N Am. 1994;78(5):1067-79.

28. Reynolds $\mathrm{JH}$, Banerjee AK. Imaging pneumonia in immunocompetent and immunocompromised individuals. Curr Opin Pulm Med. 2012;18(3):194-201.

29. Kyeyune R, den Boon S, Cattamanchi A, Davis JL, Worodria W, Yoo $\mathrm{SD}$, et al. Causes of early mortality in HIV-infected TB suspects in an East African referral hospital. J Acquir Immune Defic Syndr. 2010;55(4):446-50.

30. Cuenca-Estrella M, Bassetti M, Lass-Flörl C, Rácil Z, Richardson M, Rogers TR. Detection and investigation of invasive mould disease. J Antimicrob Chemother. 2011;661:i15-24.

31. Simpkins SA, Chan AB, Hays J, Pöpping B, Cook N. An RNA transcription-based amplification technique (NASBA) for the detection of viable Salmonella enterica. Lett Appl Microbiol. 2000;30(1):75-9.

32. Antinori S, Radice A, Galimberti L, Magni C, Fasan M, Parravicini C. The role of cryptococcal antigen assay in diagnosis and monitoring of cryptococcal meningitis. J Clin Microbiol. 2005;43(11):5828-9.

33. McManus EJ, Jones JM. Detection of Trichosporon beigelii antigen cross-reactive with Cryptococcus neoformans capsular polysaccharide in serum from a patient with disseminated Trichosporon infection. J Clin Microbiol. 1985;21(5):681-5.

34. Cheng MP, Nguyen TT, Parkes LO, Dufresne PJ, Sheppard DC. Crossreacting Ustilago maydis causing false-positive cryptococcal antigen test results. J Clin Microbiol. 2017;55(10):3135-7.

35. Nalintya E, Kiggundu R, Meya D. Evolution of cryptococcal antigen testing: what's new? Curr Fungal Infect Rep. 2016;10(2):62-7.

36. Donnelly JP, Chen SC, Kauffman CA, Steinbach WJ, Baddley JW, Verweij $P E$, et al. Revision and update of the consensus definitions of invasive fungal disease from the European Organization for Research and Treatment of Cancer and the Mycoses Study Group Education and Research Consortium. Clin Infect Dis. 2020;71(6):1367-76.

37. Tanaka K, Miyazaki T, Maesaki S, Mitsutake K, Kakeya H, Yamamoto $Y$, et al. Detection of Cryptococcus neoformans gene in patients with pulmonary cryptococcosis. J Clin Microbiol. 1996;34(11):2826-8. 
38. Paschoal RC, Hirata MH, Hirata RC, Melhem Mde S, Dias AL, Paula CR. Neurocryptococcosis diagnosis by PCR method. Rev Inst Med Trop Sao Paulo. 2004;46(4):203-7.

39. Esher SK, Zaragoza O, Alspaugh JA. Cryptococcal pathogenic mechanisms: a dangerous trip from the environment to the brain. Mem Inst Oswaldo Cruz. 2018;113(7):e180057.

\section{Publisher's Note}

Springer Nature remains neutral with regard to jurisdictional claims in published maps and institutional affiliations.
Ready to submit your research? Choose BMC and benefit from:

- fast, convenient online submission

- thorough peer review by experienced researchers in your field

- rapid publication on acceptance

- support for research data, including large and complex data types

- gold Open Access which fosters wider collaboration and increased citations

- maximum visibility for your research: over $100 \mathrm{M}$ website views per year

At BMC, research is always in progress.

Learn more biomedcentral.com/submissions 